DOI:10.5216/cab.v11i3.6174

\title{
EFEITO DO PERFIL SOROLÓGICO PARA DIARREIA VIRAL BOVINA (BVD) NAS TAXAS DE DESCARTE EM REBANHOS LEITEIROS
}

\author{
Luciano Bastos Lopes, ${ }^{1}$ João Paulo Amaral Haddad, ${ }^{2}$ Cristiano Barros Melo ${ }^{3}$ E \\ Rômulo Cerqueira Leite ${ }^{2}$ \\ 1. Pesquisador - Embrapa, Mato Grosso. E-mail: lb.lopes@yahoo.com.br \\ 2. Professor adjunto da Universidade Federal de Minas Gerais, Brasil \\ 3. Professor adjunto da Universidade de Brasília, Brasil.
}

RESUMO

\begin{abstract}
Algumas doenças infecciosas são potencialmente capazes de comprometer a viabilidade de uma produção de leite economicamente sustentável. Este trabalho teve como objetivo avaliar a relação entre a soropositividade para diarreia viral bovina (BVD) nas taxas de descarte em 240 rebanhos leiteiros comerciais. Para quantificar os efeitos da infecção pelo vírus da BVDV nas taxas de descarte involuntário, as variáveis foram incluídas em modelos
\end{abstract}

mistos de regressão linear múltipla generalizado. A soropositividade diminuiu o número de animais descartados nos rebanhos positivos de acordo com os resultados encontrados neste trabalho. A presença de anticorpos em virtude da infecção natural teve um efeito protetor contra o descarte involuntário, demonstrando o efeito da imunidade de rebanho.

PALAVRAS-CHAVES: Anticorpo, bovino, descarte, diarreia viral bovina, epidemiologia.

\section{ABSTRACT}

\section{EFFECT OF THE SEROLOGICAL PROFILE FOR BOVINE VIRAL DIARRHEA ON CULLING RATES IN DAIRY HERDS}

Some infectious diseases are potentially capable of compromising the viability of an economically sustainable milk production. The aim of this paper was to evaluate the relationship between the seropositivity status of bovine viral diarrhea (BVD) in 240 comercial herds and culling rates. To quantify the effects of $\mathrm{BVD}$ virus (BVDV) infection on culling rates, the variables were included on multiple generalizaded linear models. According to the results of this study, seropositivity decreased culling rates in positive herds. Presence of antibodies due to natural infection had a protector effect against involuntary culling rates showing the herd immunity effect.

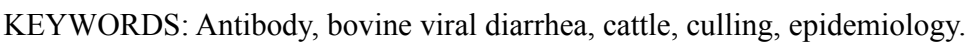

\section{INTRODUÇÃO}

A criação de bovinos em grande escala e a intensa movimentação que frequentemente ocorre nesses rebanhos os tornam mais susceptíveis aos mais diversos agentes infecciosos, por causa de uma ampla diversidade de fatores. A presença do BVDV tem frequentemente causado distúrbios ligados à reprodu- ção, fato este já documentado desde os anos 1940 por OLAFSON et al. (1946), em sua primeira descrição clínica da doença. Abortos, mumificações, perdas embrionárias e nascimentos de bezerros malformados e fracos resultam em quedas no desempenho reprodutivo do rebanho e consideráveis perdas econômicas em rebanhos bovinos (MCCLURKIN et al., 1984; AMES, 1986; BOLIN, 1990; DUBOVI, 1994; BERENDS 
et al., 2008). O BVDV pode infectar outras espécies como ovinos (SCHERER et al., 2001), além de vários outros ruminantes domésticos, incluindo caprinos e búfalos (HAMBLIN \& HEDGER, 1979; BECHER et al., 1997).

Durante os últimos sessenta anos, discussões acerca da patogênese do vírus têm criado muita confusão, em parte pela falta do completo entendimento da sua biologia. A resposta à infecção parece ser dependente da interação de uma série de fatores, sendo alguns deles inerentes aos animais, como idade do feto, estado imune do rebanho, diversidade genética do vírus e sua virulência (HOUE, 1999).

A quantificação exata dos danos após a infecção é bastante difícil, pois a maioria dos estudos têm se baseado na ocorrência de surtos da doença. Apenas alguns trabalhos têm avaliado o impacto do vírus em alguns rebanhos sem a ocorrência de surtos e, nesse sentido, o presente trabalho teve como objetivo avaliar o impacto da BVD sobre as taxas de descarte em rebanhos soropositivos.

\section{MATERIAL E MÉTODOS}

O banco de dados utilizado para a realização do presente trabalho teve origem em um estudo de prevalência realizado em 240 rebanhos de aptidão leiteira entre os anos de 1998 e 2001. Como prérequisitos de inclusão no estudo, as propriedades deveriam fornecer um número mínimo de animais necessários para amostra, ter um controle zootécnico sobre o rebanho e participar de um programa de controle leiteiro.

No total, coletaram-se 6.662 amostras de sangue durante o estudo. Paralelamente, com o auxílio de questionários, informações complementares tais como raça dos animais, número de lactações, dias em lactação no momento da coleta, época do parto, número de animais no rebanho e histórico de vacinações foram incluídos no banco de dados. A metodologia utilizada para a coleta de dados em todos os rebanhos foi a mesma, sendo possível, dessa forma, o agrupamento de todas as variáveis em uma única planilha com o auxílio do software de análises

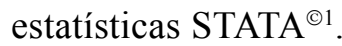

1 STATA - C Copyright 1996-2008 StataCorp LP - College Station, Texas, USA
Coleta de amostras

A partir de uma análise computadorizada, geraram-se números de forma aleatória, para que fossem selecionados, de cada rebanho, trinta animais em lactação de forma completamente randomizada, excluindo-se, no entanto, animais que já haviam sido vacinados. As amostras de sangue foram coletadas em 240 rebanhos oriundos dos seis Estados selecionados para realização de testes para detecção de anticorpos contra BVDV. Para o cálculo do tamanho da amostra requerida pelas análises estatísticas, assumiram-se uma prevalência de rebanho de $46,1 \%$, um erro permitido de $10 \%$ e um intervalo de confiança de $95 \%$ para detectar pelo menos um animal positivo por rebanho (VANLEEUWEN et al., 2001).

Selecionaram-se nos rebanhos cinco vacas que nunca haviam sido vacinadas previamente ou cinco novilhas primíparas também sem nenhum histórico de vacinação. HOUE et al. (1995) relataram uma sensibilidade superior a $95 \%$ e uma especificidade superior a $98 \%$ ao nível de rebanho para identificação de rebanhos positivos utilizando-se esta metodologia. Obtiveram-se os dados de lactação de acordo com a lactação na qual a coleta de sangue foi realizada. Os dados obedecem a uma estrutura hierárquica de quatro níveis, ou seja, lactação, animal, rebanho e, por último, os Estados (DOHOO et al., 2003).

\section{Testes sorológicos}

Todas as amostras foram armazenadas a $-20{ }^{\circ} \mathrm{C}$ pelo período no qual todas as amostras estivessem prontas para o processamento. Titulou-se o soro proveniente dos animais não vacinados para pesquisa de anticorpos contra o genótipo do tipo I do BVDV por meio do método de soroneutralização (DEREGT et al., 1992). O rebanho foi considerado positivo para BVD quando pelo menos um animal apresentou título superior ou igual a 64 (VANLEEUWEN et al., 2006). Seguindo essa metodologia, caracterizaram-se os rebanhos como positivos independentemente da frequência de animais soropositivos dentro do rebanho.

Variáveis

Incluíram-se as variáveis relativas ao perfil sorológico no banco de dados de acordo com os re- 
sultados do teste de soroneutralização. As restantes foram incluídas de acordo com as informações contidas no questionário formulado para coleta de dados complementares. Em seguida, calculou-se uma nova variável a partir das variáveis disponíveis, porcentagem de animais descartados no rebanho. A variável dependente, taxa de descarte, foi transformada em logaritmo, em razão de ajustes para realização das análises estatísticas.

Análises estatísticas

Para quantificar os efeitos da infecção pelo BVDV nas taxas de descarte, as variáveis foram incluídas em modelos mistos de regressão linear múltipla generalizado. As análises contemplam dois níveis hierárquicos, sendo as variáveis latentes no nível animal e as variáveis randômicas no nível de rebanho (DOHOO et al., 2003).

As análises foram divididas em três etapas. $\mathrm{Na}$ primeira, avaliou-se a associação estatística entre os determinantes e a variável dependente de interesse. Nesta fase, construiu-se um modelo inicial contendo todas as variáveis de interesse biológico, selecionando-as, então, a partir de sua significância estatística (Backward Elimination) (DOHOO et al., 2003). Na segunda etapa, verificou-se, segundo critérios biológicos, a associação causal entre as variáveis selecionadas na primeira fase, para verificar se havia algum fator de confundimento presente no modelo inicial (DOHOO et al., 2003). Por fim, a terceira etapa consistiu na elaboração do modelo de regressão final, para que fossem possíveis avaliar a associação causal e quantificar a influência da soropositividade dos rebanhos nas taxas de descarte involuntário. O modelo definitivo incluiu as seguintes variáveis: logaritmo do percentual de animais descartados como variável dependente, Estado onde foi realizada a coleta, número de lactações e o resultado da sorologia para BVD. Apesar de não haver associação estatística para o número de lactações, esta variável foi mantida no modelo, pois foi considerado um fator de confundimento segundo os critérios utilizados por DOHOO et al. (2003).

Controlaram-se, dessa maneira, os efeitos de rebanho, o Estado de origem dos animais e número de lactações. O logaritmo da variável dependente foi utilizado na análise para que a distribuição dos resíduos se aproximasse da distribuição normal segundo a curva de distribuição de Gauss. O limite de significância estatística convencionado neste trabalho, assim como ocorre em grande parte da literatura científica, foi de $5 \%(\mathrm{P}<0,05)$.

\section{RESULTADOS E DISCUSSÃO}

No modelo de regressão linear, foram calculados os coeficientes referentes às variáveis envolvidas nas taxas de descarte de animais em virtude da infecção pelo BVDV. De acordo com o coeficiente encontrado para variável dependente, rebanhos soropositivos para BVD apresentam um decréscimo nas taxas de descarte (-.1201595), ou seja, há uma redução de $12 \%$ no número de animais descartados involuntariamente (Tabela 1). Dadas as variáveis incluídas no modelo final, foram analisados ao todo 154 rebanhos e 4.252 animais de acordo com a seleção realizada pelo programa de análises estatísticas $\mathrm{STATA}^{\odot}$.

TABELA 1. Influência da soropositividade para BVDV nas taxas de descarte

\begin{tabular}{lcccc}
\hline Variável & Coeficiente & Erro padrão & Valor de P & $95 \%$ intervalo de confiança \\
\hline Estado 2 & 0495464 & .0073823 & 0,000 & .064015 .0350775 \\
Estado 3 & -.6537622 & .0074773 & 0,000 & $-.668417-.639107$ \\
Estado 4 & -.1889571 & .0084402 & 0,000 & $-.205499-.1724146$ \\
Estado 5 & -.6353619 & .0071277 & 0,000 & $-.649332-.6213919$ \\
Estado 6 & -1.292458 & .0075546 & 0,000 & $-1.30726-1.277651$ \\
\hline Sorologia BVD $(+)$ & -.1201595 & .0043932 & 0,000 & -.12877 \\
\hline
\end{tabular}


O estudo realizado por MEYLING et al. (1990) encontrou o mesmo tipo de associação, ou seja, rebanhos soropositivos tiveram menores taxas de descarte em comparação a outros trabalhos. Questões levantadas por HOUE (1999) e MUÑOZ-ZANZI et al. (2004) podem servir de base para discussão desses resultados. Segundo esses autores, a resposta à infecção é dependente da interação de uma série de fatores, dentre eles o estado imune do rebanho. De acordo com os resultados apresentados, pode-se observar que a presença de anticorpos nos animais teve um efeito protetor, o que não seria grande surpresa, já que rebanhos negativos estão mais sujeitos à ação futura do vírus sobre a reprodução (LOHR et al., 1983; BOLIN, 1990; GROOMS, 2004). Como os problemas reprodutivos são um dos responsáveis pelos descartes involuntários, a diminuição na taxa de descarte de $12 \%$ no presente trabalho pode ser explicada em parte com base neste princípio.

BENNETT et al. (1999) encontraram uma associação negativa entre a presença de vacas não vacinadas e a queda de produtividade nesses animais, o que reforçou ainda mais a teoria de que a presença de anticorpos é determinante para que não ocorram problemas reprodutivos e queda na produção de leite. Se o descarte precoce de animais em virtude do vírus está amplamente relacionado a esses problemas, fica clara, então, a relação entre a presença de anticorpos e o aumento da sobrevida dos animais nos rebanhos soropositivos.

Em um estudo, DAVID et al. (1994) investigaram a ocorrência de surtos de BVD em rebanhos localizados na Inglaterra e encontraram um aumento de $11 \%$ no descarte involuntário de animais infectados. Em outro estudo, PRITCHARD et al. (1989) relataram a morte de $8 \%$ dos animais e o aumento de $11 \%$ no descarte precoce de animais com infecções agudas da doença em um rebanho de 183 animais em Norfolk, Inglaterra. Em mais outro estudo realizado para avaliar as perdas causadas pelo vírus, calcularam-se o risco mínimo de descarte, o risco médio e o risco máximo, sendo, respectivamente, de 2\%, 8\% e 11\% (BENNETT et al., 1999). Estas categorias representam diferenças entre a severidade das epidemias em rebanhos recentemente infectados e não são vacinados. Em propriedades onde a doença é endêmica e os animais não são vacinados, o risco de descarte involuntário foi na média menor em comparação aos estudos anteriores, ou seja, o risco encontrado foi de $2 \%$, segundo MEYLING et al. (1990).

A controvérsia de resultados é evidente de acordo com as publicações sobre o assunto. Entretanto, um ponto-chave nesta discussão não deveria ser esquecido. Trata-se do aspecto multifatorial da doença. A diversidade genética do vírus (RIDPATH et al., 1998) e sua virulência são fatores determinantes que não podem ser desconsiderados. As diferenças metodológicas também são decisivas, pois muitos trabalhos têm sido realizados durante a ocorrência de surtos da doença. Outro ponto fundamental é a presença de animais persistentemente infectados (PI) nos rebanhos. Dada a sua grande importância epidemiológica, a porcentagem de animais PI pode influenciar significativamente as taxas de descarte, por causa da queda no desempenho produtivo desses animais e maior exposição do restante do rebanho ao vírus, dada a grande eliminação de partículas virais no ambiente. Desta forma, o maior desafio viral pode desequilibrar a relação entre os fatores epidemiológicos envolvidos no processo saúde/ doença, ou seja, o equilíbrio envolvendo o agente, seu hospedeiro e o meio ambiente.

\section{CONCLUSÕES}

A soropositividade para BVDV reduziu em 12\% a taxa de descarte nos rebanhos leiteiros envolvidos no presente estudo. Sendo assim, a soropositividade para BVDV em virtude da infecção natural apresentou um efeito protetor, aumentando, consequentemente, a sobrevida desses animais. A presença de anticorpos demonstra a importância da imunidade de rebanho, reduzindo os efeitos deletérios da presença do vírus.

\section{REFERÊNCIAS}

AMES, T. L. The causative agent of BVD, its epidemiology and pathogenesis. Veterinary Medicine, v. 81, p. 848-869, 1986.

BENNETT, R. M.; CHRISTIANSEN, K.; CLIFON-HADLEY, R. $\mathrm{S}$. Modeling the impact of livestock disease on production: case studies on non-notifiable diseases on farm animals in Great Britain. Animal Science, v. 68, p. 681-689, 1999.

BECHER, P.; ORLICH, M.; SHANNON, A. D.; HORNER, G.; KONIG, M.; THIEL, H. J. Phylogenetic analysis of pestiviruses from domestic and wild ruminants. Journal of General Virology, v. 78, 1357-1366, 1997. 
BERENDS, I. M. G. A.; SWART, W. A. J. M.; FRANKENA, K.; MUSKENS, J.; LAM, T. J. G. M.; VAN SCHAIK, G. The effect of becoming BVDV-free on fertility and udder health in Dutch dairy herds. Preventive Veterinary Medicine, v. 84, p. 48-60, 2008.

BOLIN, S. R. The current understanding about the pathogenesis and clinical forms of BVD. Veterinary Medicine, v. 85, p. 11241132, 1990.

DAVID, G. P.; CRAWSHAW, T. R.; GUNNING, R. F.; HIBBERD, R. C.; LLOYD, G. M.; MARSH, P. R. Severe disease in adult dairy cattle in three UK dairy herds associated with BVD virus infection. Veterinary Records, v. 134, p. 468-472, 1994.

DEREGT, D.; SMITHSON, S.; KOZUB, G. C. A short incubation serum neutralization test for bovine viral diarrhea virus. Canadian Veterinarian Journal Research, v. 56, p. 161-164, 1992.

DOHOO, I. R.; MARTIN, S. W.; STRYHN, H. Veterinary epidemiologic research. 1. ed. Charlottetown: AVC Inc., 2003. 706 p.

DUBOVI, E. J. Impact of bovine viral diarrhea virus on reproductive performance in cattle. Veterinary Clinics of North America: Food Animal Practice, v. 10, p. 503-b514, 1994.

GROOMS, D. L. Reproductive consequences of infection with bovine viral diarrhea virus. Veterinary Clinics of North America: Food Animal Practice, v. 20, p. 5-19, 2004.

HAMBLIN, C.; HEDGER, R. S. The prevalence of antibodies to bovine viral diarrhoea/mucosal disease virus in African wildlife. Comparative Immunology, Microbiology \& Infectious Diseases, v. 2, p. 295-303, 1979.

HOUE, H.; BAKER, J. X.; MAES, R. K.; HOUE, H.; BAKER, J. Y.; MAES, R. K.; WURYASTOTI, H.; WASITO, R.; RUEGE, P. L.; LAOYD, J. W. Prevalence of cattle persistently infected with bovine viral diarrhea virus in 20 dairy herds in two counties in central Michigan and comparison of prevalence of antibody positive cattle among herds with different infection and vaccination status. Journal of Veterinary Diagnostic Investigation, v. 7, p. 321-326, 1995.

HOUE, H. Epidemiological features and economical importance of bovine viral diarrhea virus (BVDV) infections. Veterinary Microbiology, v. 64, p. 89-107, 1999.
LOHR, C. H.; EVERMANN, J. F.; WARD, A. C. Investigation of dams and their offspring inoculated with a vaccine contaminated by bovine viral diarrhea virus. Veterinary Medicine: Small Animal Clinician, v. 78, p. 1263-1266, 1983.

McCLURKIN, A. V.; LITTLEDIKE, E. T.; CUTLIP, R. C.; McCLURKIN, A. V.; LITTLEDIKE, E. T.; CUTLIP, R. C.; FRANK, G. H; CORIA, M. F.; BOLIN, J. R. Production of cattle immunotolerant to bovine viral diarrhea virus. Canadian Journal of Comparative Medicine, v. 48, p. 156-161, 1984.

MEYLING, A.; HOUE, H.; JENSEN, A. M. Epidemiology of bovine virus diarrhea virus. Revue Scientifique et Technique OIE, v. 9, p. 75-93, 1990.

MUÑOZ-ZANZI, C. A.; THURMOND, M. C.; HIETALA, S. K. Effect of bovine viral diarrhea virus infection on fertility of dairy heifers. Theriogenology, v. 61, p. 1085-1099, 2004.

OLAFSON, P.; MACALLUM, A.; FOX, F. An apparently new transmissible disease of cattle. Cornell Veterinary Medicine, $v$. 36, p. 205-213, 1946.

PRITCHARD, G. C.; BORLAND, E. D.; WOOD, L.; PRITCHARD, D. G. Severe disease in a dairy herd associated with acute infection with bovine virus diarrhea virus, Leptospira hardjo and Coxiella burnetii. Veterinary Records, v. 12, p. 625-629, 1989.

SCHERER, C. F. C.; FLORES, E. F.; WEIBLEN, R.; CARON, L.; IRIGOYEN, L. F.; NEVES, J. P.; MACIEL, M. N. Experimental infection of pregnant ewes with bovine viral diarrhea virus type-2 (BVDV-2): effects on the pregnancy and fetus. Veterinary Microbiology, v. 79, p. 285-299, 2001.

VANLEEUWEN, J. A.; KEEFE, G. P.; TREMBLAY, R.; POWER, C.; WICHTEL, J. J. Seroprevalence of infection with Mycobacterium avium subspecies paratuberculosis, bovine leukemia virus, and bovine viral diarrhea virus in maritime Canada dairy cattle. Canadian Veterinarian Journal, v. 42, p. 193-198, 2001.

VANLEEUWEN, J. A.; TIWARI, A.; PLAIZIER, J. C.; WHITING, T. L. Seroprevalences of antibodies against bovine leukemia virus, bovine viral diarrhea virus, Mycobacterium avium subspecies paratuberculosis, and Neospora caninum in beef and dairy cattle in Manitoba. Canadian Veterinarian Journal, v. 47, p. 783-786, 2006.

Protocolado em: 7 maio 2009. Aceito em: 18 jan. 2010. 